Viewpoint

\title{
Location policy and downstream mineral processing: A research agenda
}

\author{
Wouter Bam*, Karolien De Bruyne \\ Department of Industrial Engineering, Stellenbosch University, South Africa \\ KU Leuven, Faculty of Economics and Business, Warmoesberg 26, 1000 Brussels, Belgium
}

\section{A R T I C L E I N F O}

\section{Article history:}

Received 23 September 2016

Received in revised form 6 February 2017

Accepted 28 June 2017

Available online xxx

\begin{abstract}
A B S T R A C T
The mixed results from the recent implementation of a wave of policies that aim to encourage the downstream processing of minerals - mainly in developing countries - have highlighted the need for research to better guide and support policy-making in this area. Specifically, it is crucial to determine whether mineral producing countries can or should intervene in the processing location of minerals, and if so how to go about doing so. This paper highlights these concerns by broadening our understanding of the location determinants of downstream mineral processing. We argue that researchers must move beyond the more descriptive linkage theory and Global Value Chain (GVC) and Global Production Network (GPN) approaches to incorporate New Economic Geography (NEG) theories, to improve awareness of location decisions' determinants. A profound understanding of these determinants is imperative to determine policy measures capable of influencing location outcomes. This must be complemented with an identification and evaluation of the policy options available to mineral producing countries in order to attract - or maintain - downstream processing.
\end{abstract}

(c) 2017 Elsevier Ltd. All rights reserved.

\section{Introduction}

Since the 1980s, it has been argued that mineral producing countries, and developing countries endowed with minerals in particular, may be able to industrialise and diversify ${ }^{1}$ their economies further by processing minerals into final products locally (United Nations, 1984). Indeed, mineral producing countries have been implementing policies that aim to encourage or even enforce the downstream processing of minerals (Humphreys, 2013; Zhang et al., 2015; Morris et al., 2012b). Some of these policies have been quite radical. For example, the Government of Botswana has required De Beers to cut and polish its diamonds locally (Morris et al., 2012a). Similarly, Indonesia banned the

\footnotetext{
* Correspondence to: 4th Floor Mechanical and Industrial Building, Joubert Street, Stellenbosch, 7600, South Africa.

E-mail addresses: wouterb@sun.ac.za (W. Bam), Karolien.debruyne@kuleuven.be (K. De Bruyne).

${ }^{1}$ Note that another way to industrialise their economies would be an even 'wider' diversification, i.e. diversifying into completely different industries. Although this is a very valid way to reduce vulnerability and increase growth, in this paper we focus on the possible (further) development of the already existing (extractive) industries, due to the apparent policy interest in and lack of policy guidance for this approach.
}

export of unprocessed minerals (Humphreys, 2013; Beckmann, 2013) and Zimbabwe banned the export of unrefined gold (Eunomix, 2015).

While it is unlikely that such policies are implemented during a resources slump, many countries are considering pursuing this course of action during or even before the next resource boom. For example, South Africa's Department of Mineral Resources has published a "Beneficiation Strategy" (Department of Mineral Resources, 2011) that calls for local mineral processors to be granted preferential access to raw mineral products through advantageous or "developmental" prices for these local companies, placing levies or taxes on the export of unprocessed items such as diamonds and iron ore, and imposing conditions on the use of infrastructure to force the local processing of extracted minerals. Similar events have unfolded in the Philippines, where, toward the end of the last resource boom, the Government was also considering following the lead of Indonesia and issuing a ban on the export of raw commodities (Beckmann, 2013). Pressure is being applied by regional strategies such as the Africa Mining Vision (AMV), which calls for the local processing of minerals to support industrialisation and economic growth (African Union, 2009).

Some of these policies, notably, in the case of diamonds in Botswana, have been regarded as at least partially successful (Morris, 2012b). However, it has also been recognised that where 
these policies place pressure or bring about uncertainty regarding the return on investment, they may lead to reductions in foreign direct investment in the mining industries (Humphreys, 2013). There is therefore a need to carefully consider the possible impacts that any such policy might have and how countries may optimise the impact of their policies. Morris et al. (2012b) studied location policies in sub-Saharan Africa, determining that while many countries may have a general vision for ensuring the maximum benefit from their resources, some fail to articulate and implement it in a meaningful way. The same study also argued that countries have made sub-optimal decisions by not considering which downstream industries can be sustained in the medium to long term, which has often led to the support of unviable industries and at the same time, neglect of viable industries.

With this in mind, this viewpoint first explores the current research that investigates local downstream mineral processing and why it has not supported the prevention of such sub-optimal policy setting. The review identifies a significant gap in terms of understanding the economic location determinants of downstream mineral processing and, therefore, the appropriate/optimal intervention of mineral producing countries in the mineral value chain. The paper then proceeds to formulate a research agenda for addressing this gap.

\section{Literature review}

Several studies have investigated downstream mineral processing in various countries, in particular, those in the developing world. These studies have been primarily carried out in the context of linkage theory, pioneered by Hirschman (1981) and extended by authors such as Morris et al. (2012a). Linkage theory investigates the various mechanisms that can help to ensure that a mine or other extractive operations do not become an 'enclave' which fail to contribute to the local economy. Morris et al. (2012b) defines four main categories of linkages: 1) fiscal, which refer to the tax revenue collected by the municipal or national Government; 2) consumption, which refer to the demand created for various consumables in the mining region by the wages paid to mine employees; 3) production, which can include either upstream/ backward production linkages or downstream/forward production linkages; and 4) horizontal/side-stream linkages, which refer to spill over effects to other industries through the creation of public infrastructure, knowledge transfer, and demand pooling effects. Within production linkages, upstream/backward linkages refer to the local production of inputs required in mining operations such as explosives, capital equipment and protective equipment. Downstream/forward production linkages refer to the further processing of products from mining operations such as the cutting and polishing of diamonds, the type of downstream mineral processing which this article focuses on. The concept of linkages and related work has become the backbone for significant research which investigates the impact, and in particular the benefits and missed opportunities, of the mining industry (Morris et al., 2012a; Bloch and Owusu, 2012; Fessehaie 2012; Adewuyi and Oyejide, 2012; Teka, 2012).

The downstream processing of minerals and the policy issues related to it have also been primarily addressed from a linkage perspective. For example, Bocoum and Labys (1993), Lei et al. (2013) and Ivanova (2014) all take a linkage perspective. The authors use an input-output methodology based on the work of Leontief $(1936,1956)$ and apply it to the case(s) of copper in Zambia and phosphates in Morocco; various mining industries in China; and coal mining in Australia, respectively. This approach is useful for establishing what the current impact of an industry is (i.e., which linkages currently exist) but at the same time, fails to suggest which industries can and should be promoted. The main drawback of the linkage theory approach as it is used in the downstream processing literature is that it is not explanatory in nature, but rather primarily descriptive. Furthermore, by considering downstream linkages from the perspective of mining as the focal point, the scope of downstream linkages considered is usually restricted to only one or two downstream processing steps, instead of the entire downstream value chain to final products. The dominance of the linkage theory approach in the input-output form in downstream mineral processing studies has also meant that studies investigating downstream mineral processing questions often address more than one type of linkage. This is because the analytical methods such as the Leontief matrix invariably lead to the analysis of various types of linkages. This limits the depth of research that studies attain regarding downstream linkages in particular.

More recently, authors have noted some of the limitations of the linkage theory approach and aimed to address this by extending the traditional linkage theory analysis of mining activities by adding a global value chain (GVC) and global production network (GPN) analysis approach as pioneered by Gereffi and Korzeniewicz (1994), Gereffi et al. (2005) and Henderson et al. (2002). For example, Bridge (2008) highlighted some of the limits of the linkage approach and referred to the 'stalled policy debate regarding the linkages between resource extraction and socioeconomic development'. He suggested that a GPN approach could improve our understanding of linkages in the extractive industries by emphasizing the firm-state relations and their impact on development opportunities. Similarly, Morris et al. (2012b), in what is likely to be the most in-depth recent mineral study that addresses downstream linkages, combine the GVC and linkage theory perspectives in addressing the potential developmental role of the extractive industries.

However, GVC analysis is also an inherently descriptive construct, with aspects such as rents and barriers to entry, "governance", and the identification of different "types" of value chains being introduced to provide some analytical structure to the framework (Kaplinsky and Morris, 2001). The analytical GVC and GPN approaches generally employ one or more of the descriptive maps presented in Gereffi and Fernandez-Stark (2011). These are then analysed to identify what type of power relations exist in the value chain, where rents are captured and how income is distributed between the different actors. This might be useful in understanding where in the value chain firms may have an upper hand because of limited competition and which steps in the value chain have the most potential for value added (Kaplinsky and Morris, 2001). However, it provides little insight into the fundamental economic factors that underlie the location of economic activities and the viability of undertaking such activities within a country. Thus, the GVC and GPN extension does little to address the main criticism of the linkage theory approach. Though it may increase the scope of the analysis beyond one or two steps of the value chain, the extension remains a primarily descriptive methodology. Furthermore, apart from including the role of multinational firms and their interaction with local Governments in determining where mineral processing takes place, the GVC extension of linkage theory does little to connect with established economic location theory. Indeed, the methodology lacks dynamism and does not allow an understanding of and how active policies could change location outcomes.

Nonetheless, linkage theory and the GVC and GPN approaches describe the location of mineral extraction and processing and as such are useful in providing an initial insight into these location outcomes. However, better - more than merely descriptive understanding of the exact location determinants is needed in order to provide solid policy recommendations as well as to gain a fuller picture of the welfare implications of policy interventions. 
Table 1

The economic location determinants of firms.

\begin{tabular}{|c|c|}
\hline First nature (Neo-classical Trade Theories) & Second nature (New Economic Geography Theories) \\
\hline (1) Endowments of factors of production & (1) Presence of intermediate suppliers \\
\hline A. Labour & (2) Size of final market \\
\hline B. Capital & (3) Transport costs that determine the distance to suppliers/final market \\
\hline \multicolumn{2}{|l|}{ C. Technology } \\
\hline \multicolumn{2}{|l|}{ D. Raw materials } \\
\hline E. Energy & \\
\hline
\end{tabular}

(2) Geography of the country (e.g. landlocked or not)

Source: De Bruyne (2006).

Indeed, there still exists a theoretical gap when it comes to explaining the apparent lack of downstream linkages in many developing mineral producing countries. As Morris et al. (2011) explain 'there is an almost complete absence of data and supporting analyses on the nature and determinants of existing patterns of linkages which can be used to inform actions for the future'.

Various other studies have already identified factors which likely affect the location of the downstream processing of minerals that go beyond the linkage theory and are therefore more predictive and explanatory in nature. One of these studies is, the United Nations (UN) 'Mineral Processing in Developing Countries' study published in 1984 (UN, 1984). Similar to the premise of this paper, the study examined 'the factors which affect the location of mineral processing in developing countries' and identified two broad categories. First, 'technical and economic elements affecting the viability of a project' e.g. capital, skilled labour, raw materials, complementary inputs, energy, economies of scale, technological change, growth in demand, proximity to export markets and transport costs. And second, 'structural elements' (e.g. sources of finance and technology, trade and investment and taxation policies). However, similar to other studies, the UN study stopped short of determining the relative importance of the various factors that influence the downstream processing of minerals or connecting them to established economic location theory. Rather, each of the factors were considered qualitatively and in an isolated manner. In contrast, several studies do measure the importance of different location determinants - as well as their interaction - for economic activity in general (De Bruyne, 2010; ; Mion, 2004; Hanson, 2005 De Bruyne, 2010; Mion, 2004; Hanson, 2005). However, this literature has not yet been integrated with the mineral resource literature and policy debates. Crucial to the research agenda is therefore a better understanding of the theoretically-underpinned location determinants to evaluate the effectiveness of the policy instruments aimed at influencing mineral processing location. The various economic factors that may influence the location of firms in general - and therefore also of downstream mineral processing in particular - can be loosely divided into two main categories, as shown in Table 1 (De Bruyne, 2006). Both first and second nature location determinants are derived from well-known trade and economic geography models (see Fujita et al., 1999).

The first nature theories are exogenous - implying that they determine the location of a firm directly. Indeed, Neo-Classical Trade Theories (NCT) propose that firms might want to settle in countries with raw materials or a high-skilled labour force. If it is important for them to ship their final or intermediate products at low cost, they may want to locate in a country with a major harbour or (hub) airport. Although NCT theories were originally developed to explain trade patterns between countries, they automatically affect location outcomes.

The second nature theories are endogenous - implying that they induce a snowball effect. In the New Economic Geography
Theories (NEG) the location of economic activity is determined by 'centripetal' and 'centrifugal' forces. Centripetal forces pull firms towards the centre of economic activity. Such forces occur in the presence of e.g. suitable factors of production, easy access to markets, and benefits from increasing returns to scale. Conversely, centrifugal forces push firms away from the centre of economic activity. Examples are negative externalities such as congestion. The NEG theories analyse when firms prefer to locate in the centre of economic activity and when they prefer to move to the periphery, depending on the strength of these forces. The snowball effect (caused by centripetal forces) can best be explained using an example. Final producers want to locate close to their intermediate suppliers, with a view toward providing an important market for these intermediate suppliers and therefore attracting even more intermediate suppliers to the country (or to the centre in this case). These new intermediate suppliers in turn will attract new final producers. In the end, a cluster of final producers and intermediate suppliers will emerge. It is important to understand that the snowball effect and centripetal forces may be counterbalanced by centrifugal forces. Indeed, if for instance due to congestion, production becomes too expensive, firms may prefer to leave the centre of economic activity. The cluster will therefore remain as long as the centripetal forces (cluster benefits) outweigh the centrifugal forces (congestion).

Given the importance of location determinants as captured in the first and second nature theories, Governments and policymakers can intervene to increase or counteract the impact of these determinants. The degree to which they can make a difference depends on the key factors that are relevant for a specific region and industry as well as the resources and power at their disposal. Baldwin et al. (2005) identify three categories of interventions that policymakers may pursue to influence location outcomes. ${ }^{2}$ These are shown in Table 2.

It is therefore argued here, that an improved understanding of the key location determinants at play is crucial to determine which policy instruments within these three categories would be suitable to pursue in a given context. It is obvious that all three policy interventions have a direct (first-nature) impact on location. As a practical example of policy-related location determinants one and two, it may be argued that by cutting taxes on labour or investing in education, Governments may attract firms that require semi- or high-skilled labour. Linking back to downstream mineral processing, a Government might, for instance, opt to invest in education such that it becomes more lucrative for a downstream mineral processing firm requiring skilled labour to locate in the country. Take the case of manganese production. As far as the extraction itself is concerned, low- skilled labour is a crucial input factor. In further stages downstream in the value chain (e.g. alloy, electrolytic manganese dioxide and electrolytic manganese metal

\footnotetext{
2 Baldwin et al. (2005) focus on the impact of public policy under second nature theories (snowball effects). It is however obvious that these policies may also have
} an initial impact under first nature theories. 
Table 2

Categories of location interventions available to policy makers.

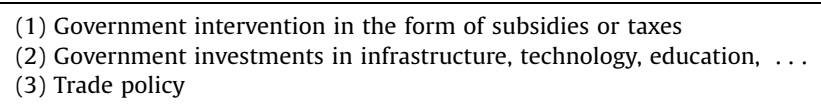

Source: Baldwin et al. (2005).

production), semi-skilled labour is required. If the Government therefore opts to educate its local labour force, it might be able to attract downstream mineral processing. By giving incentives to export, Governments might also attract exporting firms within their borders and/or stimulate domestic firms to export more in a particular stage of the value chain. This constitutes an example of a policy-related location determinant, as shown in Table 2. One concrete example is the Chinese industrial policy on the rare earth element (REE) industry, implemented in 2010, which imposed export duties and export quotas on REE exports. However, the EU, US and Japan challenged this policy at the WTO (World Trade Organisation) and the WTO ruled against China in 2014 . $^{3}$

Baldwin et al. (2005) illustrate that under second nature location theories, Government policy may even have a larger impact on location. Indeed, given the snowball effect, a small Government intervention may have a large final impact. Linking back to downstream mineral processing, a Government might temporarily subsidise part of the downstream mineral processing industry and thus start a snowball effect attracting more and more final and intermediate producers. Indeed, if a country manages to attract a processing stage in the global value chain, it might attract more processing stages later on and even other related and unrelated industries.

From both policy examples, it is obvious that developing countries will unfortunately not always be able to pursue their preferred policy. First of all, they might face financial constraints to, for example, increase subsidies or decrease taxes. Second, as a member of the WTO, they have to take WTO rules into account when they develop their trade policies. Nonetheless, despite these constraints, the analysis of optimal policies to attract downstream mineral processing remains highly important for developing countries. Relating to the financial constraint, defining optimal policies is crucial to; (i) understand how developing countries could improve their situation in the most cost-effective manner that could lead to a sustainable competitive advantage; and (ii) understand how international organizations might best help the development of these countries cost-effectively. Linking to the limitations as far as trade policy is concerned, the WTO already allows many wavers for developing countries. Indeed, developing countries are given longer timetables for implementing many important provisions and commitments precisely in order to allow them to protect nascent industries should they choose. However, in order to grant such exceptions, the WTO requires convincing arguments for which industries these exceptions are 'justified'. A thorough understanding of the key location determinants is therefore indispensable.

The ultimate question remains whether countries or regions have already been successful in implementing policies addressing location issues in general, aside from just the case of mineral resources. Similar to downstream mineral processing policy, Anderson (2012) defines regional policy in general as public sector interventions designed to prevent peripheral, less developed regions that are often specialized in the production of resource-based commodities from falling behind. Examples of strategies to obtain these objectives include investment in human

\footnotetext{
${ }^{3}$ Note that Zhang et al. (2015) show that although the duties and quotas had to be removed, China substantially increased the market power of its REE industry.
}

capital and infrastructure - policies that are based on economic location determinants, as discussed in Table 1 . Such regional policy programmes have been adopted in a variety of countries over the past few years. For example, programmes have been implemented to assist the northeast region of Brazil and several (lagging) European regions. The main goal of the European Regional Policy is to eliminate regional economic disparities. Empirical evidence about whether this goal has been achieved is, however, mixed at best. Moreover, these policies were not aimed at particular sectors. Indeed, apart from very specific cases discussed in the introduction, ${ }^{4}$ the identification and analysis of first or second nature policy measures within the context of downstream mineral processing has been lacking. A better understanding of why firms set up their activities in a particular location - and the linkages this implies makes for a more solid analysis of policy measures than the existing approaches discussed.

\section{Setting the research agenda}

Given the context provided in the previous section, it is argued that to arrive at a sound policy framework regarding the governance of downstream mineral processing, three interrelated areas of research need to be developed. First, it is crucial to map and understand the current distribution of mineral processing activities globally. Second, there is a need to test theories explaining the global distribution of mineral processing activities. Third, the various policy options that are available to mineral producing countries need to be identified and their merits and demerits evaluated in different circumstances.

To expand, the global distribution of extracting activities - as well as the downstream mineral processing - has to be mapped based on the available trade and production data. The key at this stage is to select the appropriate minerals for investigation in order to arrive at generalizable results for key mineral types. In other words, the case selection will have to be such that the minerals chosen are representative of economically important groups of minerals. For each extracting activity, as well as for each stage of downstream mineral processing, the production share needs to be calculated in every country so as to establish which production stages are currently located where. This stage will provide the empirical backdrop for the following two research areas. In a second stage, the economic location determinants need to be defined and the theories that explain the global distribution of mineral processing activities need to be tested. In order to define the economic location determinants, information from input/ output tables as well as information from industry surveys should be combined. Once the possible location determinants are known, one can turn to testing the theories. In particular, the current linkage theory and GVC and GPN approaches, as applied by both Morris et al. (2012b) and Bridge (2008) have to be enriched by applying theoretically underpinned location theories. Specifically, (i) NCT theories are needed to understand the impact of various national factor endowments on the location of mineral processing activities, and will have to be combined with (ii) a NEG approach to account for the snowball effect observed in various global value chains. As examples, see De Bruyne (2010) for an ANOVA analysis to determine the relative importance of the NCT/NEG theories, or Sukkoo (1999) and Amiti (1999) for an analysis to determine the importance of NCT theories. It is obvious that the economic location determinants will vary among countries, industries, and different stages in the value chain within industries.

Once the economic location determinants are fully understood and tested for, one can move to the policy part of the research

\footnotetext{
${ }^{4}$ Diamonds in Botswana, Gold in Zimbabwe, REE in China.
} 
agenda. In a third stage, the policy options available to mineral producing countries in order to attract downstream mineral producing activities have to be identified based on the primary economic location determinants. Special attention also needs to be paid to the feasibility of these policies - as underlined in the previous section. This stage also has to include an investigation and evaluation of policies that have already been implemented by different countries with extractive industries.

\section{Conclusion}

The recent increase in the implementation of various policies that aim to encourage or even force the downstream processing of minerals has highlighted the need for research to better inform policy makers. Specifically, it is crucial to be able to determine whether and how mineral producing countries can and should intervene in the processing location of minerals. This paper has highlighted the need to move beyond the linkage theory and the GVC and GPN approaches to incorporate trade and economic geography theories in order to gain a complete picture of the economic location determinants. A profound understanding of the location determinants is imperative to determine the appropriate policy measures to influence these location outcomes. Finally, this has to be complemented by an identification and evaluation of the policy options available/attainable to mineral producing countries in order to attract - or maintain - the downstream processing of minerals. It is contended that this approach will lead to the development of improved policy recommendations for mineral dependent developing countries seeking to expand the downstream processing of minerals and thus help to increase the value that they attain from their mineral resources.

\section{References}

Adewuyi, A.O., Oyejide, Ademola T., 2012. Determinants of backward linkages of oil and gas industry in the Nigerian economy. Resour. Policy 37 (4), 452-460.

African Union, 2009. Africa Mining Vision. .

Amiti, M., 1999. Specialisation patterns in Europe. Weltwirtschafliches Arch.134 (3), 573-593.

Anderson, W.P., 2012. Economic Geography. Routledge Taylor and Francis Group.

Baldwin, R., Forslid, R., Martin, P., Ottaviano, G., Robert-Nicoud, F., 2005. Economic Geography and Public Policy. Princeton University Press.

Beckmann, R., 2013. Indonesian Resource Nationalism - and the World Beyond? Coal International September.

Bloch, R., Owusu, G., 2012. Linkages in Ghana's gold mining industry: challenging the enclave thesis. Resour. Policy 37 (4), 434-442.

Bocoum, B., Labys, W.C., 1993. Modelling the economic impacts of further mineral processing. Resour. Policy 19 (4), 247-263.

Bridge, G., 2008. Global production networks and the extractive sector: governing resource-based development. J. Econ. Geogr. 8 (3), 389-419.
De Bruyne, K., 2006. The location of economic activity. First versus second nature core-periphery theories. Rev. Bus. Econ. Lit. L1 (1), 75-104.

De Bruyne, K., 2010. Explaining the location of economic activity is there a spatial employment structure in Belgium? Int. J. Econ. Issues 3 (2), 199-222.

Department of Mineral Resources, 2011. A Beneficiation Strategy for the Minerals Industry of South Africa June 2011. Tech. rep., Department of Mineral Resources of South Africa.

Eunomix, 2015. Zimbabwe's Beneficiation Policy: Understanding the Drivers and Objectives.

Fessehaie, J., 2012. What determines the breadth and depth of Zambia's backward linkages to copper mining? The role of public policy and value chain dynamics. Resour. Policy 37 (December (4)), 443-451.

Fujita, M., Krugman, P., Venables, A.J., 1999. The Spatial Economy: Cities, Regions, and International Trade. MIT Press, Cambridge, Massachusetts.

Gereffi, G., Fernandez-Stark, K., 2011. Global Value Chain Analysis: a Primer. Durhan, North Carolina, USA.

Gereffi, G., Korzeniewicz, M., 1994. Commodity Chains and Global Capitalism. Praeger, Westport, CT.

Gereffi, G., Humphrey, J., Sturgeon, T., 2005. The governance of global value chains. Rev. Int. Polit. Econ. 12 (1), 78-104. doi:http://dx.doi.org/10.1080/ 09692290500049805.

Henderson, J., Dicken, P., Hess, M., Coe, N., Yeung, H., 2002. Global production networks and the analysis of economic development. Rev. Int. Polit. Econ. 9 (3), 436-464.

Hirschman, A.O., 1981. Essays in Trespassing: Economics to Politics and Beyond. CUP Archive.

Humphreys, D., 2013. New mercantilism: a perspective on how politics is shaping world metal supply. Resour. Policy 38 (September (3)), 341-349.

Ivanova, G., 2014. The mining industry in Queensland, Australia : some regional development issues. Resour. Policy 39 (March (1)), 101-114.

Kaplinsky, R., Morris, M., 2001. A Handbook for Value Chain Research. IDRC Retrieved from http://www.prism.uct.ac.za/Papers/VchNov01.pdf.

Lei, Y., Cui, N., Pan, D., 2013. Economic and social effects analysis of mineral development in China and policy implications. Resour. Policy 38 (December (4)), 448-457.

Leontief, W., 1936. Quantitative input and output relations in the economic systems of the United States. Rev. Econ. Stat. 18 (3), 105-125.

Leontief, W., 1956. Factor proportions and the structure of American trade: further theoretical and empirical analysis. Rev. Econ. Stat. 38 (4), 386-407. doi:http:// dx.doi.org/10.2307/1926500.

Morris, M., Kaplinsky, R., Kaplan, D., 2011. Commodities and Linkages: Industrialisation in Sub-Saharan Africa. MMCP Discussion Paper No. 13.

Morris, M., Kaplinsky, R., Kaplan, D., 2012a. One thing leads to another commodities, linkages and industrial development. Resour. Policy 37 (4), 408416.

Morris, M., Kaplinsky, R., Kaplan, D., 2012b. One Thing Leads to Another: Promoting Industrialisation by Making the Most of the Commodity Boom in Sub-Saharan Africa.

Sukkoo, K., 1999. Regions, resources and economic geography: the sources of U. S. regional comparative advantage, 1880-1987. Reg. Sci. Urban Econ. 29 (1), 1-32.

Teka, Z., 2012. Linkages to manufacturing in the resource sector: the case of the Angolan oil and gas industry. Resour. Policy 37 (4), 461-467.

United Nations, 1984. Mineral Processing in Developing Countries: a Discussion of Economic, Technical and Structural Factors. Tech. rep., Natural Resources Forum, United Nations Secretariat.

Zhang, L., Guo, Q., Zhang, J., Huang, Y., Xiong, T., 2015. Did China's rare earth export policies work? Empirical evidence from USA and Japan. Resour. Policy 43, 8290 . 